\title{
Information Component of the Environmental Policy of Ukraine: Current Status and Development Potential
}

\author{
Volodymyr Haraschuk ${ }^{1}$, Yana Zelinska ${ }^{2}$, Viktoriia Spasenko ${ }^{3}$, Ievgenii Shulga ${ }^{4}$
}

\begin{abstract}
The article emphasizes the importance of the role of the information component of the environmental policy of the modern state within the context of the reorientation of human-nature relations towards sustainable development. The existing approach of the Ukrainian lawmaking body to the determination of environmental information, the features of environmental information relations and the state-regulatory mechanism of its control are analyzed. The emphasis is placed on the existing ineffective system of collecting, analyzing, processing and transmitting information, which actually brings to naught the fairly broad rights of citizens in the environmental information sphere. A new differentiated approach is proposed to determine the structural elements of the information component of the environmental policy in Ukraine, based on which the main existing gaps of the modern state policy of Ukraine in this field are emphasized. Their solutions are proposed, among which are: the creation and organizational support of the automated information and analytical systems and other objects (sources) of providing access to environmental information; optimization of the existing procedural order for obtaining environmental information by contacting the public authorities and local governments in obtaining environmental information by the interested parties; responsibility tightening of public officials of executive and local authorities for failure to comply with the requirements of the law, for the timely provision and reliability of environmental information; adaptation of the national regulatory framework to international standards for environmental management and environmental labelling of products, etc.
\end{abstract}

Keywords: information, ecology, environmental information relations, environmental policy of Ukraine, information policy of Ukraine.

\section{Introduction}

Environmental protection in the 21 st century is one of the most urgent problems. Despite attempts to reduce the destructive impact on the environment through the economy transition to "green rails", the establishment of a significant array of restrictions, prohibitions and incentives in the mechanism of legal regulation of this sphere, it was not possible to achieve significant results in the direction of greening production. In modern society, the spirit of the prevalence of economic interests over environmental interests is still preserved. Moreover, current trends in the growth of world industry show that anthropogenic pressure on nature will only increase as a result of scientific and technological progress, which in turn can lead to irreparable

\footnotetext{
${ }^{1}$ Doctor of Law, head of the Department of Administrative Law of Yaroslav Mudryi National Law University.

${ }^{2}$ Ph.D. in Law, assistant professor of the Department of Administrative Law of Yaroslav Mudryi National Law University.

${ }^{3} \mathrm{Ph} . \mathrm{D}$. in Law, assistant professor of the Department of Administrative Law of Yaroslav Mudryi National

${ }^{4}$ Doctor of Law, associate professor of the Department of International Law and Comparative Law of the National University of Life and Environmental Sciences of Ukraine.
} 
consequences. One must bear in mind the fact that the Earth is our home. We can dream as much as we wish about Mars settlement, but the change in climatic conditions on Earth will undoubtedly affect the quality and standard of living of not only humans but also other biological species. For many years now, scientists of various specialties around the world have been raising the alarm, arguing that the catastrophic consequences of an environmental nature are only a matter of time, pointing out the need for an early and fundamental change in the existing course of the relationship between man and nature.

Within the realities of the modern system of state-organized social structure, sovereign countries play a key role in the reorientation of human-nature relationships towards sustainable development. Namely at the country level, with the help of a range of legal influence mechanisms, the relatively abstract process of greening acquires a real character and implementation. And therefore, it is the success of the implementation of programs and strategies of environmental policies carried out at the national level by each individual country that is key to determine the condition of the earth's ecosystem.

It should be noted that the environmental policy of the country should be understood as the system of economic, legal and informational measures that the state takes to reduce the negative anthropogenic impact on nature [1]. Among a wide variety of measures for the implementation of the state's environmental policy, the information component plays an important role, which is not only a relatively independent course of ensuring environmental safety in the state, but also acts as a guarantee of the effectiveness of the implementation of almost all state management activities. For example, the objectives of the institute of legal responsibility in the field of environmental protection (as in any other field) are not possible to complete without adequate information support for the entire procedure for the implementation of actions system by the authorities, from the stage of identifying a law violation to the time the punishment is taken and enforced. And considering the great importance of information in the modern world, the significance of the information component of the state environmental policy is beyond dispute.

\section{The current situation of the state-management mechanism for the regulation of environmental information relations.}

The realities of the Ukrainian domestic system constitute no exception. In spite of the proclamation of the need for comprehensive environmental protection at the level of the Constitution, as well as through the ratification of the number of international environmental instruments, the environmental problems remain unresolved. The inconsistency and inefficiency of state environmental policy in Ukraine over the past decades has led to complete degradation of the environmental conditions, which, in turn, confirms the need to re-examine certain existing aspects of the information component of the environmental policy of Ukraine.

At the moment, the underlying principles and priorities of the implementation of the state policy of Ukraine in the field of ecology are defined in the Law of Ukraine "On the Basic Principles (Strategy) of the State Environmental Policy of Ukraine for the Period until 2030." The Law, among others, outstands the following as independent principles: 
the responsibility of executive authorities and local authorities for the availability, timeliness and reliability of environmental information; the introduction of the latest means and forms of communication and effective information policy in the field of environmental protection [2]. In addition to the above, the Law more than once emphasizes the importance of optimizing information support in the field of ecology.

In general, the current-day national system of legal regulation of environmental information relations is very ramified. Legal instructions for regulating the circulation of information related to environmental protection are contained in the Laws of Ukraine: "On Information", "On Environmental Protection", "On Environmental Impact Assessment", "On State Secret", and "On Ensuring Sanitary and Epidemic Welfare of the Population", "On Protection of Atmospheric Air", "On the Red Book of Ukraine", a number of regulations of the Water, Forestry Codes and many other regulatory legal acts of different legal force. However, despite a rather significant array of regulatory legal acts devoted to the regulation of environmental information relations, the level of fulfilment of the objectives of the state policy of Ukraine in the field of ecology remains far from perfect. Legal acts often duplicate each other's provisions, and the absence of a single codified act in the field of ecology, which the "Environmental Code" could become (the adoption of which has been repeatedly emphasized in the scientific community [3, 4]), leads to repeated manifestation duplication of the same provisions, and sometimes to conflicts of laws.

There are many examples of such gaps. Today, even the lawmaking body's approach to the determination of the category of "environmental information" is not without lowlights. So, the Law of Ukraine "On Information" operates on the category "information on the condition of the environment (environmental information)", which means - information and/or data on: - the condition of the components of the environment and its content, including genetically modified organisms, and the interaction between these elements; factors that influence or may affect the components of the environment (substances, energy, noise and radiation, as well as activities or measures, including administrative, environmental agreements, policies, laws, plans and programs); the state of health and safety of people, people's living conditions, the condition of cultural facilities and structures, provided that they have been affecting or may be affected by the condition of the components of the environment; other information and/or data (art. 13) [5]. While the lawmaking body uses a slightly different interpretation in the Law of Ukraine "On Environmental Protection", which already uses the term "Information on the condition of the environment (environmental information)", which is understood as: "any information in written, audiovisual, electronic or other material form on: the condition of the environment or its elements land, water, mineral resources, atmospheric air, flora and fauna and their level of pollution; biological diversity and its components, including genetically modified organisms and their interaction with elements of the natural environment; the sources, factors, materials, substances, products, energy, physical factors (noise, vibration, electromagnetic interference, radiation) affecting or likely to affect the condition of the environment and human health; the occurrence threat and causes of emergency environmental situations, the results of the elimination of these phenomena, recommendations on measures aimed at reducing their negative impact on natural 
objects and human health; the environmental forecasts, plans and programs, events, including administrative ones, state environmental policy, legislation on environmental protection; the expenses associated with the implementation of environmental measures at the expense of environmental protection funds, other sources of financing, economic analysis carried out in the decision-making process on issues related to the environment" (art. 25) [6]. Despite the differences in the content, these definitions are essentially synonyms and it remains unclear why the lawmaking body does not use a single term for the entire system of legal regulation of environmental information relations, thereby increasing the likelihood of a double interpretation of the category "environmental information". We believe that such a gap in the legal technique of the national lawmaking body is caused, first of all, by the variability of the translation of foreign acts. Please note that there is no such multiplicity in international documents. Both the Aarhus Convention and Directive 2003/4/EEC, as well as other documents, traditionally use the term "environmental information" [7, 8]. In its turn, "environmental" means "the natural world, surroundings" (hence the difference in the approaches of the national lawmaking body). There are a significant number of such inconsistencies in the system of national legislation related to the regulation of environmental information relations.

This state of the legislative framework for regulating the relations under study is caused not only by inaccuracies and errors committed in the process of legal technology (although, of course, by them as well) but also by the most complex two-part nature of environmental information relations. In practice, this leads to the fact that the legislation of this area is developed separately both in the direction of information and environmental security. In addition, such a symbiosis of information and environmental principles (read as industries) often leads to a conflict of industry priority. So, despite the system-forming and system-organizing role of information law as a branch of law noted by scientists [9], the peculiarities of the legal regulation of environmental information relations arising in the field of nature management and environmental protection are associated with the imposition of techniques, methods and means of environmental law on the mixed method of legal regulation of information law. Moreover, this process operates in the reverse order.

This order of things, of course, affects the lawmaking process, turning it into a constant search for a balance between the ratio of public law and private law principles in environmental and information law and legislation, conflict of public and private interests.

\section{Elements of the information component of the environmental policy of Ukraine.}

Having regard to the above, for the successful implementation of the information and environmental policy of Ukraine, from our point of view, it would be efficient to consider the complex of relations associated with the information assurance of the environmental policy of Ukraine more differently, namely through the spectacle of its main structural elements - relatively independent elements (directions) of legal regulation related by the solidarity of objectives and the similarity of the applied public- 
administrative enforcement actions. We call your attention to that the independence of the proposed elements is very conditional and made for a more simplified understanding of the complex structured information component of the environmental policy.

\section{A set of state and administrative measures to support the implementation of the access right to environmental information.}

The ability to exercise access rights to information is the key "pillar", the hallmark of open democracy and at the same time one of the backbone institutes of environmental information policy in Ukraine. The Constitution of Ukraine guarantees everyone the right of free access to information about the state of the environment, as well as the right to disseminate such information. The particular importance of ensuring free access to this information is emphasized by the constitutional ban on any restriction of environmental information (see Art. 50) [10].

The issue of ensuring that citizens exercise their rights to obtain information about the condition of the environment is still widely debated not only among domestic legal scholars but also within the scientific area of the developed European countries. Thus, jurisprudence in Western Europe interprets the right to a healthy and clean environment as a right formalized and consisting of three parts: the access right to environmental information; the right to participate in the environmental decision-making; the access right to justice. Having secured the right of everyone to access environmental information in the Directive on the freedom of access to information on the environment (90/313/EEC) in 1990, the international community has also emphasized the absence of the need to confirm the interest of the person who applied for environmental information. In addition, having established that information provision may be refused only in exceptional, narrowly limited cases, if, for example, the issues of international relations, national defence, public security or the secrecy of meetings of state organizations are raised. The refusal to provide information should be clarified. It can be appealed in court. The Directive is based on the idea that state organizations should share with the public information on the state of the environment, which serves as the basis for decisions on actions (measures) or decisions to stay inactive [11]. Subsequently, at the EU level, the above Directive was replaced by Directive 2003/4/EC "On Public Access to Environmental Information" [8], which, apart from the above said guarantees, obligated public bodies to actively disseminate environmental information. It is noteworthy that a minimum list of information was established, the accessibility of which should be ensured in electronic form [8], at the same time, a set of measures to ensure access to environmental information belonged to the prerogative of the state.

In the following years and by this day, international acts on protecting the human and civil rights to access environmental information keep developing. In 2015, the "International Open Data Charter" was adopted at the summit of the Open Government Partnership, which was subsequently adjusted by Ukraine at the national level [12].

Ukraine provides a wide array of state-management measures and assurances for the exercise of the access right to environmental information. And in general, the state of the regulatory framework in recent decades has significantly improved in this area. That is 
evidenced by the exclusion of Ukraine from the list of violators of the Aarhus Convention in 2017 after the adoption of the Law of Ukraine "On Environmental Impact Assessment" [13]. However, despite the positive steps of Ukraine in this direction, a number of problematic issues remained unresolved. For example, the timeliness of the preparation by the central executive body, implementing state policy in the field of environmental protection, of the annual National Report on the State of the Environment and the systematic informing of the population through the media about the current environmental situation, leaves much to be desired. So, there is only a draft structure of the National Report on the State of the Environment for 2018 on the official website of the Ministry of Energy and Environmental Protection of Ukraine at the moment, although it is obvious that in the first half of 2020 it would be necessary to publish information on the state of the environment for 2019. There is also a big problem regarding the systematic disclosure of environmental information by other competent state bodies and local authorities. In particular, environmental information is not regularly delivered through the media, and there is no possibility of getting familiarized with relevant environmental information on specially created automated information-analytical systems of public authorities and local government bodies [14].

The existing feedback model of public bodies and interested parties regarding the latest environmental information being received is also ineffective. The provision of information on requests for information is provided in Sec. IV of the Law of Ukraine "On Access to Public Information". The information controller must provide a response to the request for information no later than five business days from the date of receipt of such a request. In practice, complaints are often received that majority of answers to requests are provided pro forma but are not specific, do not contain an answer to the issues raised, or the formal note on the lack of data on a particular situation.

The remarkable thing is that the state management measures to ensure the implementation of the access right to environmental information should also include the institution of legal responsibility and the right to judicial protection and protection of the access rights to environmental information in an administrative procedure. So, in accordance with the Article 212-3 of the Code of Ukraine on Administrative Offences ("Violation of the right to information and the right to appeal"), an illegal refusal to provide information, untimely or incomplete provision of information, provision of untrue information, in cases where such information is to be provided at the request of a citizen or legal entity in accordance with the laws of Ukraine "On Information", "On Citizens' Appeals" and "On Access to Judicial Decisions", entails administrative penalties. Apart from this general provision, the Code of Administrative Offences also contains a special regulation, thus indicating the importance of information on the state of the environment. So in accordance with the Art. 91-4 of the Code of Administrative Offences "refusal to provide or untimely provision, upon request, of complete and reliable environmental information provided for by the law, entails a fine on officials from three to ten tax-free minimum incomes of citizens" [15].

In Yu.S. Shemshuchenko's opinion, the right to environmental information is a guarantee of the enforcement of the right to environmental safety, and therefore, if it is violated, the law provides not only for its reopening but also compensation for material and moral damage, if any. The amount of compensation is determined by the court 
(Article 49 of the Law "On Information"). [16] Such a right is exercised not only by private entities but also by government bodies on the basis of the Art. 25-1 of the Law of Ukraine "On Environmental Protection" by preparing the annual National Report on the State of Environment in Ukraine by a central executive body that implements the state policy in the field of environmental protection with its subsequent submission to the Verkhovna Rada of Ukraine.

Based on the foregoing, we believe that today, it is advisable to single out the following, as the most desirable growth direction areas of the national mechanism guaranteeing the access right to environmental information:

1) creation and organizational support of automated information-analytical systems and other objects (sources) of providing access to environmental information;

2) optimization of the existing procedural order for obtaining environmental information by interested parties' contacting the public authorities and local governments for obtaining environmental information;

3) tightening the responsibility of officials of executive and local authorities for failure to comply with the requirements of the law for the timely provision and reliability of environmental information;

4) adaptation of the national regulatory framework to international standards for environmental management and environmental labelling of products.

\section{The instrument for the legal regulation of relations related to the collection, analysis, processing and transmission of environmental information during the performance of the public and local authorities' duties.}

State management activities for the collection, analysis and processing of information is, in fact, the backbone within the coordinate system of the entire information component of the environmental policy of the state. Without a proper collection of information, it is impossible to fully realize the state's obligations to its citizens in the environmental field, and indeed to carry out any action with information as a resource.

The main instrument used by the state for the collection, analysis and processing of information is state monitoring. As follows from its content, "monitoring" is a method of researching an object, which involves tracking and monitoring its activities (functioning) in order to predict the latter [17].

The Decree of the Cabinet of Ministers of Ukraine "On the Approval of the Regulation on the State Monitoring System" identified the key focus areas of the environmental monitoring system, namely: increasing the level of study and knowledge about the ecological state of the environment; improving the efficiency and quality of user information service at all levels; improving the quality of substantiation of environmental protection measures and the effectiveness of their implementation; assistance in the development of international cooperation in the field of environmental protection, rational use of natural resources and environmental safety [18]. In addition to monitoring, a crucial aspect of the direction under consideration is the audit and other control and supervisory activities of the state (product certification, licensing, etc.). 
As of this date, the first-priority role is given to comprehensive monitoring of the environmental activities of economic entities. In the General Table (List) of State Statistical Monitoring Forms for Enterprises, the following reporting forms are established: No. 2-TP (air) "Report on Atmospheric Air Protection" (annual, quarterly); No. 1-environmental costs "Environmental Costs and Environmental Charges" (annual); No. 1-waste "Waste Management" (annual) [19]. It should be noted that in the developed countries of the world according to statistics, $80 \%$ of the 250 largest companies draws non-financial reports, and in developing countries, $45 \%$ from 2.2 thousand enterprises. Unlike the international practice in Ukraine, only 10\% among the 100 largest enterprises draws and publishes such reports [20]. Non-financial reports recognized as the standard in the international community, such as the UN Global Compact Progress Report (Communication on Progress - COP) or the Sustainable Development Report of the Global Reporting Initiative (Global Reporting Initiative GRI) in Ukraine do not have wide application.

The Concept of the State Program for Environmental Monitoring stated that one of the reasons for the extremely difficult environmental situation in Ukraine is the poor functioning of the state environmental monitoring system [21]. At the same time, there are a lot of practical challenges in the functioning of the regional environmental monitoring system, which consist in the fragmentation of the monitoring services and, accordingly, the "dissipation" of information among them. This leads to the fact that only a small part of the available information is actually used. We should point out that this issue is escalated by the methodological incompatibility of the observations of some departmental services. Also, the insufficient development of the observation network, the technical and moral obsolescence of the material resources of the laboratories of most monitoring entities leads to the inability to determine the real degree of environmental pollution, the lack of control in the work of polluting enterprises, the continuation of their emission of hazardous substances, and the like.

Largely due to the state of monitoring activities in the country, we also have challenges with access to the information mentioned above. An ineffective system of collecting, analyzing, processing and transmitting information actually negates the fairly broad rights of citizens in the environmental information field. We believe that the issues associated with monitoring in Ukraine are global in nature and require a comprehensive review of the entire existing system.

\section{Development of environmental culture and awareness among the population through environmental education and promotion of environmental values}

The population education of environmental culture and consciousness is the most important area of state informational environmental policy of Ukraine. We agree with N.N. Moiseev, who has noted that everyone should have environmental knowledge, equal to arithmetic, regardless of specialty and nature of work, country and skin colour [22]. The famous Italian ecologist A. Traverso spoke about the importance of the role of education in the development of the ecological culture of the population. The scientist claimed that environmental education is an essential component of the formation of a new strategy for public education that meets the needs of humanity and nature [23]. 
Unfortunately, the general negative tendency in the education system of Ukraine is also critical for the field of environmental education. The environmental education system in Ukraine continues to be fragmented (unsystematic), conceptually weak, declarative, and, therefore, ineffective. This is due to the fact that environmental issues do not fit well into the system of market relations. The ecological world outlook is focused on other values human life in a clean environment, the preservation of all living forms. The critical situation in the field of environmental education is explained by such reasons as the long-term dominance of consumer attitudes towards nature; ignorance and destruction of folk traditions of rational nature management; underestimation of environmental knowledge in the education system; low level of implementation in practice of the achievements of pedagogical science; weak material and technical and methodological support of the educational process [24].

In accordance with the provisions of the "Concept of Environmental Education in Ukraine", the necessity was determined for the formation of ecological culture of all segments of the population; training of environmental specialists for various sectors of the national economy; improvement, coordination and standardization of terminology in the field of environmental knowledge [25]. However, state-management instruments to improve the level of environmental education and culture have not actually been introduced. And financing to this day is carried out mainly from foreign sources. Environmental nonprofit organizations continue to play the primary role in this direction. Some of them issue periodic publications, for example, Green World (Ukrainian Ecological Association "Green World"). Some of the organizations, in particular Ekopravo-Kiev, Ekopravo-Lvov, Ekopravo-Kharkov and others, advise the public on environmental legislation, are engaged in educational and other activities [26]. The lack of full state participation in the outlined issue significantly slows down the increase in the level of environmental culture and education of Ukrainians. It should also be noted that the media and educational institutions remain the best way to deliver environmental information to the masses. And therefore, the effectiveness of the targeted promotion of environmental values with the support of the state is the crucial step on the path of Ukraine greening. Moreover, in the current economic instability of Ukraine, the attractiveness of the development of this particular area is confirmed by its relatively inexpensive cost and high efficiency in comparison with other environmental protection measures. Agree, it's much cheaper to promote the environment than, for example, to allocate large subsidies for the development of the field of "sound energy" (although the author also considers it necessary).

\section{Conclusions}

Summing up the above analysis, it should be said that in addition to those highlighted, there are many more issues in the informational environmental policy of Ukraine. In this paper, we drew attention only to the most acute and significant of them. Ukraine stands in front of a long way connected with both developing a more effective state environmental policy and implementing it. We consider the underlying directions for the development of environmental information policy in Ukraine to be as follows:

1) creation and organizational support of automated information-analytical systems and 
other objects (sources) of providing access to environmental information; 2) optimization of the existing procedural order for obtaining environmental information by interested parties' contacting the public authorities and local governments for obtaining environmental information; 3) tightening the responsibility of officials of executive and local authorities for failure to comply with the requirements of the law for the timely provision and reliability of environmental information; 4) adaptation of the national regulatory framework to international standards for environmental management and environmental labelling of products; 5) comprehensive review of the entire existing monitoring system; 6) distribution of non-financial reports of enterprises on sustainable development, which are popular with the world community; 7) full participation of the state in the issue of improving environmental culture and public education through the promotion of environmental values.

\section{References}

1. Rogozh M.M. (2015) Environmental ethics in civil society: theoretical and applied aspects. Scientific journal Forest Herald. Volume 19, Number 4, PP. 64-69.

2. Law of Ukraine of February 28, 2019 No. 2697-VIII About the Basic principles (strategy) of the state environmental policy of Ukraine for the period till 2030 // Official Bulletin of the Verkhovna Rada. - 2019. - No. 16. - Art.70.

3. Andreitsev, V. I. (2012) Improvement of Environmental Law: Conceptual Framework. Materials of the International Round Table "Experience and Problems of Improvement of Environmental Legislation", dated December 14, 2012, Dnipropetrovsk: materials. - Dnipropetrovsk, 2012. - P. 5 27.

4. Hetman, A. P. (2016) Codification of environmental legislation in the context of constitutional reform. Environmental Law of Ukraine. - Volume 1-2. - PP. 3-5.

5. Law of Ukraine of 02.10.1992 No. 2657-XII On Information. Official Bulletin of the Verkhovna Rada of Ukraine. No. 48 - art. 650.

6. Law of Ukraine of June 1991 No. 1264-XII On the Protection of the Environment. Official Bulletin of the Verkhovna Rada of Ukraine]. No. 41. - art. 546

7. Convention on Access to Information, Public Participation in Decision-making and Access to Justice in Environmental Matters (1998) [Aarhus Convention]. URL: https://www.un.org/ru/documents/decl_conv/conventions/orhus.shtml.

8. Directive 2003/4/EC of the European Parliament and of the Council of 28 January 2003 on public access to environmental information and repealing Council Directive 90/313/EEC. URL: http://data.europa.eu/eli/dir/2003/4/oj.

9. Bachilo, I. L (2016) Information Law: A Textbook for Academic Undergraduate Studies / M.: Urait Publishing House, P. 419

10. Constitution of Ukraine of 28.06 .1996 No. 254k/96-VR. Official Bulletin of the Verkhovna Rada of Ukraine. - 1996.- No. 30.- p. 141.

11. Arkhipov, A. M. (2009) Specific guarantees of the right of citizens of the Russian Federation to environmental information. Legal issues of communication. Volume 2. PP. 22.

12. The International Open Data Charter. (2016) URL: https://zakonst.rada.gov.ua/images/opendata/docs/opendatacharter_UKR.pdf

13. Information Agency "Unian" (2017) URL: https://www.unian.net/ecology/naturalresources/2136754ukrainu-vyicherknuli-iz-spiska-narushiteley-orhusskoy-konventsii-oon-minprirodyi.html.

14. Cheremnova, A. I. (2017) Topical issues of exercising the right to environmental information in Ukraine. Scientific journal Comparative-analytical law. Volume 2. PP. 109-111

15. Code of Ukraine on Administrative Offenses (1984): Law of Ukraine of 07.12.1984 No. 8073-X Official Bulletin of the Verkhovna Rada of Ukraine. Addendum to No. 51. - art. 1122

16. Shemshuchenko, Yu. S. (1989) Legal problems of ecology. Kiev. - 231 p.

17. Sociological Encyclopedia (2003). Head of scientific project G. Yu. Semgin. - M.: Mysl. PP. 694. 
18. Concept of the State Program for Environmental Monitoring (2004). Decree of the Cabinet of Ministers of Ukraine of December 31, 2004 No. 992-r // URL: https://www.kmu.gov.ua/npas/10717911.

19. General Table (List) of State Statistical Monitoring Forms for Enterprises for 2019. Order of the State Statistics Service "On Approval of the General Table (List) of State Statistical Monitoring Forms for Enterprises for 2019” of 17.05.2019 No. 161, amended // URL: http://www.ukrstat.gov.ua/norm_doc/2019/161/161_2019.htm.

20. What the non-financial report are silent of. Information resource "Delo". URL: http://delo.ua.

21. Regulations on the state monitoring system of the environment. Resolution of the Cabinet of Ministers of Ukraine of March 30, 1998. No. 391. URL:https://zakon.rada.gov.ua/laws/show/391-98$\% \mathrm{D} 0 \% \mathrm{BF} /$ conv.

22. Moiseev, N. N. (2000) The Fate of Civilization. The Path of Mind. - M.: Languages of Russian culture. 224 p.

23. Tolstoukhov, A. V., Khylko, M. I. (2001) Eco-friendly development: the search for strategies. - K.: Knowledge of Ukraine. P. 179

24. Krysachenko, V.S., Khylko M. I. (2001) Ecology. Culture. Politics: conceptual foundations of modern development. - K :: Znannia, 2001. 598 P.

25. Concept of Environmental Education of Ukraine (2001). Approved by the Decision of the Board of the Ministry of Education and Science of Ukraine Minutes No. 13/6-19 of 20.12.2001.

26. Committee on Environmental Policy of the European Economic Commission (2007). Review of environmental performance. Ukraine. Second review. - United Nations - New York and Geneva $2007-247$ p. 